\title{
Review Article \\ Cellular Signaling and Potential New Treatment Targets in Diabetic Retinopathy
}

\begin{abstract}
Zia A. Khan and Subrata Chakrabarti
Received 28 December 2006; Revised 2 May 2007; Accepted 13 September 2007

Recommended by Timothy Kern

Dysfunction and death of microvascular cells and imbalance between the production and the degradation of extracellular matrix (ECM) proteins are a characteristic feature of diabetic retinopathy (DR). Glucose-induced biochemical alterations in the vascular endothelial cells may activate a cascade of signaling pathways leading to increased production of ECM proteins and cellular dysfunction/death. Chronic diabetes leads to the activation of a number of signaling proteins including protein kinase C, protein kinase B, and mitogen-activated protein kinases. These signaling cascades are activated in response to hyperglycemia-induced oxidative stress, polyol pathway, and advanced glycation end product formation among others. The aberrant signaling pathways ultimately lead to activation of transcription factors such as nuclear factor- $\kappa \mathrm{B}$ and activating protein- 1 . The activity of these transcription factors is also regulated by epigenetic mechanisms through transcriptional coactivator p300. These complex signaling pathways may be involved in glucose-induced alterations of endothelial cell phenotype leading to the production of increased ECM proteins and vasoactive effector molecules causing functional and structural changes in the microvasculature. Understanding of such mechanistic pathways will help to develop future adjuvant therapies for diabetic retinopathy.
\end{abstract}

Copyright (c) 2007 Z. A. Khan and S. Chakrabarti. This is an open access article distributed under the Creative Commons Attribution License, which permits unrestricted use, distribution, and reproduction in any medium, provided the original work is properly cited.

\section{INTRODUCTION}

Diabetic retinopathy (DR), the most common cause of blindness in the working population, is also the most frequent manifestation of the diabetic microvascular disease $[1,2]$. Nearly all people with type 1 and more than half with type 2 diabetes develop retinopathy [3]. Retinal complications in chronic diabetes may culminate from microvascular dysfunction, neuroglial abnormalities, and metabolic imbalance including the lack (type 1) or excess (type 2) of insulin. Microvascular alterations comprise of microvascular endothelial cell (EC) dysfunction, vessel leakage, and occlusions. Clinically, DR can be classified as nonproliferative DR (NPDR) and proliferative DR (PDR) [3-7]. NPDR is structurally characterized by capillary basement membrane (BM) thickening, pericyte loss, microaneurysms, increased permeability, exudate deposits, and retinal microinfarcts [3-7]. Diabetic macular edema may lead to significant visual impairment in NPDR. Also NPDR has further been divided in progressive stages: mild, moderate and severe. The later stages (sometimes also called preproliferative retinopathy) show increased retinal damage as evidenced by increased retinal vascular blockage and infarcts. If left untreated, proliferative retinopathy characterized by abnormal neovascularization in the retina develops. The devastating outcome of the proliferative retinopathy is hemorrhage and tractional retinal detachment.

Although it has been customary to consider a common origin of microvascular disease in both type 1 and type 2 diabetes, recent evidence suggests considerable heterogeneity in the development and progression among the two populations. Clinical studies reveal that vision threatening retinopathy is usually because of neovascularization in type 1 and maculopathy in type 2 patients $[8,9]$. Clinical trials have shown that good glycemic control can reduce the development of retinopathy in both type 1 [10] and type 2 [11] diabetic patients. Current treatment for PDR and maculopathy is carried out by laser photocoagulation which prevents further loss of vision. However, these therapeutic modalities are ineffective against restoring diminished visual acuity. Understanding the molecular basis of DR pathogenesis may offer better therapeutic regimens. Towards this aim, investigators have studied the effects of high glucose levels in animal models of the disease and cultured cells. These in vivo and in vitro models do not fully recapitulate the disease process observed in humans. The proliferative stage of the DR has not been observed in the well studied rodent models. However, both the in vitro and the in vivo models do offer insight into 
the early molecular changes which may dictate the more advanced stages of the disease. This review will highlight some of these findings in both cultured vascular ECs and animal models of diabetes with an emphasis on cell signaling and the early molecular changes mediating microvascular alterations in DR.

\section{STRUCTURAL AND FUNCTIONAL CHANGES IN DR}

\subsection{Alteration of vasoactive effector molecules}

Vasoactive effector molecules play important roles in both early and late stages of DR. Hyperglycemia leads to increased vasoconstriction and impaired endothelium-dependent vasodilation [12-20]. Increased expression of endothelin-1 (ET-1), the most potent vasoconstrictor, has been shown in diabetes (reviewed in [13]). Increased ET-1 mediates vasoconstriction in the retina which is readily prevented by inhibiting ET receptor signaling [19]. In cultured cells, we have also shown that ET-1 increases EC permeability and extracellular matrix (ECM) protein expression [13, 2123] possibly through protein kinase $\mathrm{C}$ (PKC) activation [24].

Endothelium-dependent vasodilatory responses have been shown to be dampened in diabetics [14-18]. Data accumulated to date indicates increased levels of endothelial (e-) and inducible (i-) nitric oxide synthase (NOS) enzymes in response to high levels of glucose $[25,26]$. Such a phenomenon is also evident in animal and human diabetes (reviewed in [27]). In addition, a number of molecular pathways which are altered in diabetes may increase the activity of NOS enzymes; these include vascular endothelial growth factor (VEGF) [28], and PKC and protein kinase B signaling pathways [28-30]. A few theories can be formulated to account for the discrepancy between increased NOS expression/activity, NO levels and impaired vasodilation. Increased NO production but decreased bioavailability may be one explanation. Secondly, ET-induced vasoconstriction may overwhelm the vasodilatory action of NO. In the context of diabetic milieu (increased ET levels and oxidative stress), NO may also mediate other cellular activities such as EC proliferation as suggested by the increased NO level observed during the proliferative phase of DR. Finally, NO function may be influenced by heme oxygenase-1 (HO-1) [25]. We have shown that diabetes causes oxidative DNA damage in several tissues including the retina and alter blood flow through the induction of HO-1 [25, 27, 31]. HO-1 agonist in ECs and animals mimics the effects of high glucose and diabetes by increasing NOS levels.

An extensive interaction exists among these vasoactive effector molecules which determine the expression/production and function of the respective molecule $[13,26]$. Taken together, these studies have shown that alteration of these vasoactive effector molecules may be instrumental in the production of early changes in DR such as blood flow alterations, increased permeability, and ECM deposition, eventually leading to nonperfusion of the retinal tissue.

\subsection{Cellular dysfunction and death-effect on retinal vascular function}

One early event in DR is the loss of pericytes from capillaries and venules $[32,33]$. Pericyte loss is believed to contribute to the earliest clinically visible manifestation of DR, microaneurysms [34]. This loss may occur due to increased oxidative stress, toxicity from high levels of glucose, and other factors. Recently, autoantibodies against pericytes have been detected in the sera of diabetic patients $[35,36]$. Loss of pericytes may not only affect the vascular tone but may also lead to EC phenotypical changes. The integral communication between ECs and contractile cells of the vascular wall is increasing being realized (for review, see [37-39]). In addition to the indirect role of pericytes in producing EC dysfunction, high levels of glucose may directly lead to EC damage and loss $[13,26,40]$.

Retinal fluorescein angiography has revealed areas of nonperfusion in DR $[41,42]$. Comparing the results from these studies with retinal digest experiments $[43,44]$, it is evident that most nonperfused areas in the retina have degenerative pericytes and ECs. These findings may suggest that retinal vascular perfusion is dependent on intact endothelium $[45,46]$. Although numerous studies can be cited which demonstrate abnormal platelet function in diabetes, attempts to modify the function have produced much disappointment (reviewed in [47]). Platelets isolated from diabetic animals were shown to be more adherent to the diabetic vasculature than platelets from nondiabetic animals [48]. Thrombocytopenia produced by administering antiplatelet serum caused further retinal blood barrier breakdown [48]. However, assessing other features of DR has revealed no beneficial or deleterious effects of selective antiplatelet drug clopidogrel [49]. These findings indicate that the platelet function may be altered in diabetes; however, the exact role played by the platelets is not clear. More recently, leukocytes were shown to adhere to retinal vasculature [50] and mediate capillary occlusion in streptozotocin-induced diabetic rats [51]. The levels of adhesion molecules (ICAM and VCAM) as assessed by nonquantitative immunohistochemical techniques were shown to be increased or unchanged [52, 53]. Soluble forms of these adhesion molecules have been reported to be higher in the vitreous of patients with PDR [54]. Furthermore, exposure of ECs to either tumor necrosis factor- $\alpha$ or advanced glycation end products increases the expression of VCAM [55] providing a mechanistic basis in diabetes.

Sustained hyperglycemia is related to increased vascular permeability $[56,57]$. Permeability studies in type 1 and hypertensive type 2 diabetic patients have revealed increased albumin flux through the endothelium [58-65]. The direct cellular and molecular mechanism is still obscure; in part, due to our inability to adequately assess vascular permeability unambiguously. In cultured cells, however, we have shown that glucose- and ET-1 induced EC permeability can be normalized by PKC inhibition [24]. It is believed that a dysfunction in the transfer property of the endothelium occurs, which when precipitated with occlusion, leads to under- or nonperfusion. These areas of nonperfusion, in conjunction 
with cellular damage, may trigger a reparative response; a finding well documented in retinal microcirculation [40].

\subsection{Capillary basement membrane (BM) thickening}

A consistent feature of DR is thickening of the capillary BMs [66-71]. Capillary BM thickening can result from increased production and decreased degradation of the extracellular matrix (ECM) proteins $[67,69]$. High levels of glucose $(30 \mathrm{mM})$ can increase mRNA expression of ECM proteins, collagen and fibronectin (FN), in the kidney mesangial cells and the retinal ECs [72-74]. Retinal BMs of diabetic animals have been shown to contain increased collagen $\alpha 1$ (IV), and $\beta 1$ and $\gamma$ chains of laminin, and FN [75]. These changes are brought upon as early as 8 weeks following onset of diabetes [75]. We have also shown that diabetes increases ECM protein expression in the kidney, retina, and heart of streptozotocin-induced diabetic rats $[21,76,77]$. In addition to collagen $\alpha 1$ (IV) and FN, upregulation of other ECM proteins such as tenascin has been found in retinal vessels of diabetic patients and animals $[78,79]$. However, no difference has been shown in the amount of proteoglycans in BMs of patients with DR [80].

Recently, we have demonstrated that FN undergoes alterative splicing in DR to produce an embryonic isoform $\mathrm{ED}-\mathrm{B}^{+}$ FN (oncofetal FN) [81]. Increased levels of this isoform are evident in vitreous of patients with PDR and retinal tissues of diabetic rats. This isoform is normally absent in normal adult tissues and may be involved in functional effects via outsidein signaling [22]. In cultured vascular ECs, we have shown that $\mathrm{ED}-\mathrm{B}^{+} \mathrm{FN}$ is involved in VEGF expression and EC proliferation suggesting an important role of this FN isoform in DR.

\section{MOLECULAR MECHANISMS OF DR PATHOGENESIS}

DR is a culmination of numerous biochemical alterations which take place in the vascular tissue of the retina. High levels of glucose affect both the vascular ECs and the pericytes. The retinal ECs incorporate glucose via glucose transporter1 induced facilitative diffusion [82-84]. Therefore, increased circulating levels of glucose accumulate in the retinal ECs and lead to activation of various biochemical pathways. It is possible that other factors, such as hyperinsulinemia and dyslipidemia, may also contribute to the abnormal signaling in DR. In this review, we will explore the diabetes-induced molecular alterations in the retina and glucose-induced changes in cultured ECs in an attempt to identify novel therapeutic targets for DR.

\subsection{Aldose reductase (AR) and the polyol pathway}

Hyperglycemia-induced secondary complications of diabetes are particularly evident in tissues which are not insulinsensitive such as the retinal vasculature. Under normal conditions, glucose utilization is primarily through the glycolytic pathway. However, in diabetes excessive glucose is metabolized by the polyol pathway/aldose reductase (AR) enzyme. Increased AR activity is implicated in the development of sec- ondary diabetic complications $[85,86]$. Glucose flux through the polyol/AR pathway may lead to sorbitol accumulation [86] and accompanying cellular damage [86, 87] which may be prevented by myo-inositol supplementation [88]. It is believed that increased NADH production, a cofactor for glyceraldehyde 3-phosphate dehydrogenase, leads to augmented levels of glyceraldehyde 3-phosphate. Thus, polyol pathway may also contribute to advanced glycation end product formation through methylglyoxal from increased glyceraldehydes 3-phosphate [89].

Supplementing these experimental evidences of the involvement of AR enzyme in diabetic complications, clinical studies show that polymorphisms in AR gene are linked to increased susceptibility of microvascular complications [9092]. Clinical trials to assess AR inhibition as a therapeutic modality have not shown any conclusive results. One recent trial with AR inhibitor sorbinil showed slower rate of microaneurysms in the retina [93]. Recently, however, a new class of AR inhibitors was tested in streptozotocin-induced diabetic rats [94]. This selective inhibitor, ARI-809, was as effective in AR inhibition in the animal model as sorbinil. Whether ARI809 produces more favorable results in clinical trials remains to be determined.

\subsection{Oxidative stress}

Oxidative stress early in the disease state may contribute to EC dysfunction and may also be the driving force in the continued insult to the retinal vasculature during the later stages of the disease. The mechanisms which may underlie increased oxidative stress in ECs and retinal tissues in diabetes are complex and interconnected (Figure 1) [26]. The early pathways of oxidative stress, which may initiate the EC dysfunction and pave the path for continued vascular damage, include glucose auto-oxidation and mitochondrial superoxide production [95-97]. Inhibiting mitochondrial superoxide production has been shown to be beneficial for DR [97].

Oxidative stress in diabetes may also be induced by indirect means, which include the NADPH oxidase enyzme $[98,99]$. NADPH oxidase may increase superoxide production and through induction of xanthine oxidase may also inhibit superoxide dismutase. Impairment of antioxidant enzymes could also be carried out by increased AR activity through the imbalance between $\mathrm{NADP}^{+} / \mathrm{NADPH}$. A number of other enzymes have also emerged as being important mediators of increased oxidative stress. Lipoxygenase enzyme (LOX) may also contribute to diabetes-induced oxidative stress. LOX increases oxidation of low density lipoproteins (ox-LDLs) [100, 101]. We have shown that glucose increases CD36 (an ox-LDL receptor) and leads to increased uptake of ox-LDL and oxidative DNA damage in vascular ECs [100].

Recently, several investigators have shown a role of poly (ADP-ribose) polymerase (PARP) in cultured ECs and retina of diabetic animals [102-104]. Increased PARP activity, possibly in response to oxidative DNA damage, may directly cause vascular EC dysfunction via the depletion of $\mathrm{NAD}^{+}$ and ATP. PARP may also cause nuclear factor $-\kappa \mathrm{B}(\mathrm{NF}-\kappa \mathrm{B})$ 


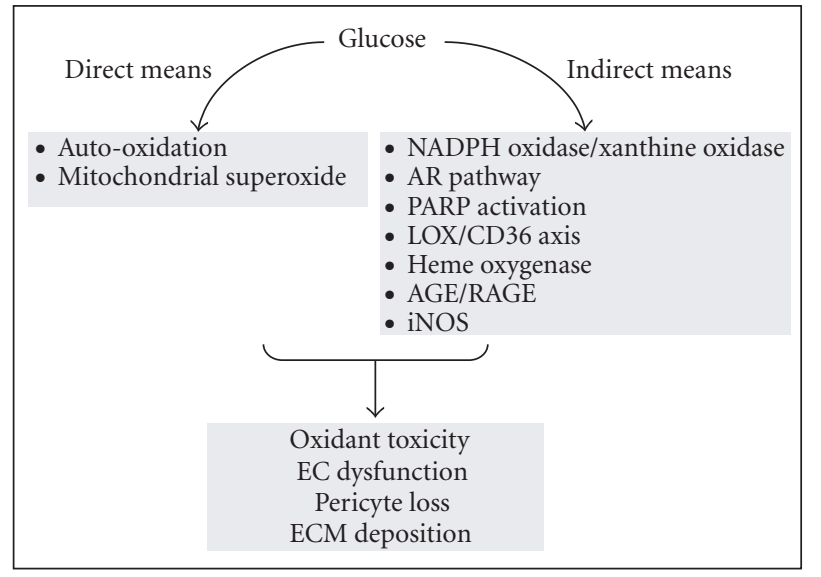

FIGURE 1: Mechanism and consequence of increased oxidative stress in DR (NADPH, nicotinamide adenine dinucleotide phosphate; $\mathrm{AR}$, aldose reductase; LOX, lipoxygenase; PARP, poly(ADP-ribose) polymerase; AGE, advanced glycation end product; RAGE, receptor for AGE; iNOS, inducible nitric oxide synthase).

activation [105]. In a nondiabetic system, a relationship between PARP activation, histone deacetylases (HDACs) and transcription coactivator p300 has been shown [106, 107]. Whether a similar pathway may also be involved in DR requires further investigation.

\subsection{Protein glycation}

Protein modification has also been shown to play an important role in diabetic complications. Glucose may participate in nonenzymatic glycation of proteins to produce advanced glycation end products (AGEs) [108, 109]. Both AGEs and AGE receptors (termed RAGEs) have been localized to the retinal vasculature and vascular ECs [110-113]. Although the means by which AGE/RAGE cause cellular dysfunction are currently being elucidated. It is believed that AGEs may lead to altered protein function, interfere with the ECM function, and cause elaboration of cytokines. In cultured ECs, AGE formation has been reported to regulate thrombomodulin, ET-1, VEGF, and basic-fibroblast growth factor [114-116]. Administration of exogenous AGEs to diabetic animals show retinal pericyte loss [117]. Retinal ECs, however, proliferate in response to glycated BMs [118]. These studies provide insight into the mechanism of pericyte loss and unregulated EC proliferation in the later stages of the disease. Experimental studies in diabetic animals show that a specific inhibitor of nonenzymatic glycation, aminoguanidine, can prevent retinal microaneurysms, acellular capillaries, and pericyte loss in the diabetic dogs [119].

\subsection{Protein kinase C (PKC) activation}

Exposure of cultured ECs to high levels of glucose leads to rapid induction of a number of protein kinase family members $[23,24,120,121]$ suggesting that these proteins may play a role in transducing the adverse effects of hyperglycemia in the retinal vasculature. Several studies have shown the acti- vation of an important protein kinase, PKC [122] in the context of diabetes $[23,24,122-124]$. PKC isoforms which show significant activation in animal models of chronic diabetes include PKC $\alpha, \beta \mathrm{I}, \beta \mathrm{II}, \gamma$, and $\delta[125,126]$. However, PKC $\beta \mathrm{I}$ and II show the highest level of induction in the retina as well as the heart and aorta of the diabetic animals [126]. The mechanism of PKC activation may involve increased diacylglycerol (DAG) levels which have been shown in the retina of diabetic animals [127] and vascular cells exposed to high glucose levels [126, 127]. DAG can be increased through the hydrolysis of phosphatidylinosities or through de novo synthesis. Fatty acid composition analysis of DAG reveal that the major contributor to increased DAG in hyperglycemic conditions may be the de novo synthesis or phospholipaseD mediated production of DAG $[127,128]$. PKC activation, either directly or through interaction with other intracellular signaling proteins, may cause a number of vascular effects which are summarized in Figure 2. We and others have previously shown that PKC may mediate glucose-induced EC permeability [24, 129], and ECM protein production [23]. In addition, PKC may be involved in the expression of various growth factors and vasoactive factors, and regulate cellular activity [122, 124, 129-131]. A tremendous amount of work has also been done on the activation of PKC secondary to alteration of growth factors and cytokines. One of the best examples is the activation of PKC through VEGF which is highly relevant to DR. VEGF mediates cellular signaling in ECs through binding to VEGF receptors (VEGFR1 and VEGF-R2). Upon binding of VEGF, VEGF-Rs signal the release of DAG (through glycolytic pathway intermediates) [132]. This DAG increase causes activation of selective $\mathrm{PKC}$ isoforms (predominantly $\beta$ isoform) and mediates the vasoregulatory role of VEGF such as permeability [133]. Invitreal injection of VEGF rapidly increases PKC activation in the retina. Furthermore, the VEGF-mediated retinal permeability can be normalized with PKC- $\beta$ inhibition [133]. We have shown a similar interaction between PKC and ET-1 [24]. Several experimental and clinical studies have been carried out with selective $\mathrm{PKC} \beta$ inhibitor, ruboxistaurin mesylate (LY333531) [133-138]. In phase III clinical trials ruboxistaurin showed a delay in the occurrence of moderate visual loss in patients with NPDR at 24 months [139].

\section{EMERGING TARGETS}

\subsection{Mitogen-activated protein kinase (MAPK)}

PKC may also regulate the vascular function in chronic diabetes through interaction with other signaling complexes in the vascular ECs. Recently, studies have reported an important role of MAPK pathway in the diabetic complications $[140,141]$ which may, in part, be dependent upon PKC activation [23]. MAPK family consists of extracellular signalregulated kinase (ERK) and stress- activated components, namely c-jun N-terminal kinase (JNK) and p38 (for review, see $[140,142])$. MAPK activation proceeds through sequential activation of MAPKKK, MAPKK, and MAPK [142]. We have shown that glucose-induced ECM protein synthesis in ECs may be mediated by the activation of MAPK 


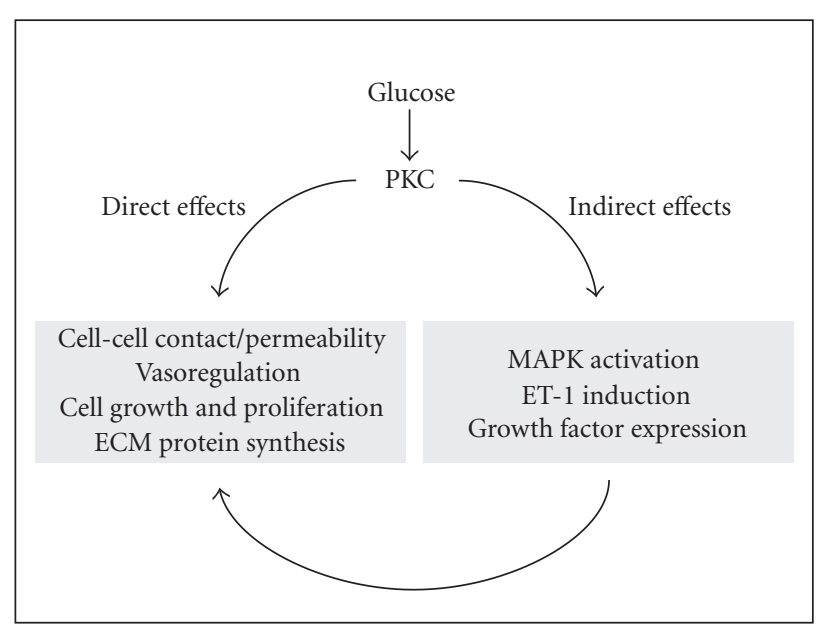

FIGURE 2: Role of PKC in vascular function in diabetes (DAG, diacylglycerol; PKC, protein kinase C; ECM, extracellular matrix; MAPK, mitogen-activated protein kinase; and ET-1, endothelin-1).

[23]. We have further demonstrated that such MAPK phosphorylation leads to activation of transcription factors NF$\kappa \mathrm{B}$ and activating protein-1 (AP-1) [23]. Inhibition of either MAPK or PKC is able to normalize the effects of high levels of glucose. Furthermore, inhibiting PKC in cells exposed to high glucose reduces MAPK activation suggesting an important cross-regulation between PKC and MAPK. ECM protein expression through MAPK activation has also been reported in renal tubular cells [143] implicating a role of MAPK in diabetic nephropathy as well [144]. It is, however, possible that MAPK activation may also occur via a PKC-independent pathway [145]. Oxidative stress may cause alternate MAPK activation via ERK5 (big MAPK1/BMK1) [146]. BMK1 knockout results in angiogenic defect and embryonic lethality [147]. BMK1, however, differs from other MAPK as it contains a transcriptional activation domain, mediating protein-protein interaction with several other factors $[147,148]$. Whether such pathways are also activated in diabetes remains to be determined.

\subsection{Activation of other protein kinases}

Most recent developments in the attempt to elucidate the signaling events in cultured ECs challenged with high levels of glucose have revealed a role of significantly homologous protein kinase family members, protein kinase B (PKB), [120] and serum- and glucocorticoid-regulated kinase-1 (SGK-1) [121]. Several growth factors stimulate the recruitment of lipid kinases known as Class I phosphoinositide 3-kinases ( $\mathrm{PI}_{3}$-kinase) to the plasma membrane. These kinases then phosphorylate the glycerophospholipid phosphatidylinositol 4,5-bisphosphate (PtdIns $(4,5) \mathrm{P} 2)$ converting it to PtdIns $(3,4,5) \mathrm{P} 3$ (reviewed in $[149,150]$ ). Evidence indicates that serine/threonine protein kinase PKB may be the key mediator of several downstream events regulated by $\mathrm{PI}_{3}$-kinase. There are three major PKB isoforms $\alpha, \beta, \gamma$. These isoforms belong to a subfamily of protein kinases named AGC pro- tein kinases and include PKC and PKA. Following activation of $\mathrm{PI}_{3}$-kinase, $\mathrm{PKB}$ isoforms are recruited to the plasma membrane and are phosphorylated by phosphoinositidedependent kinase 1 (PDK-1). PKB can regulate the function of cytoplasmic as well as nuclear proteins $[149,150]$. We have demonstrated glucose-induced early activation of PKB [120] and SGK-1 [121]. Inhibiting PKB and SGK-1 either by dominant negative transfections and/or small interfering RNA causes complete normalization of high glucose-induced FN expression in the vascular ECs. This role of PKB in ECM protein expression is regulated by both MAPK and PKC [120]. We have further shown that $\mathrm{PKB}$ phosphorylation can lead to the activation of NF- $\kappa \mathrm{B}$ and AP-1 [120].

\subsection{Transcription factors}

All extracellular and intracellular signals converge on transcription factors to regulate various aspects of vascular function in diabetes. Two of the major transcription factors which have been shown to be instrumental in mediating the effects of diabetes are NF- $\kappa \mathrm{B}$ and AP- 1 . In nonstimulated cells, NF$\kappa \mathrm{B}$ exists as a latent dimer in the cytoplasm being bound to $\mathrm{I} \kappa \mathrm{B}$, an inhibitor protein. Upon stimulation, $\mathrm{I} \kappa \mathrm{B}$ kinase (IKK) is activated and leads to phosphorylation and subsequent degradation of $\mathrm{I} \kappa \mathrm{B}$. Without the inhibitory $\mathrm{I} \kappa \mathrm{B}, \mathrm{NF}-\kappa \mathrm{B}$ translocates to nucleus and affects gene expression by binding to $\kappa \mathrm{B}$ elements in their promoter region [151]. Oxidative stress is one of the main activators of NF- $\kappa \mathrm{B}$ [151]. Interestingly, glucose-induced ET-1 expression may be regulated via NF- $\kappa$ B activation [152]. Studies have indicated nuclear NF- $\kappa$ B immunoreactivity in the pericytes but not retinal vessel ECs of human diabetic eyes [153]. Experimental evidence in diabetic animals, however, shows NF- $\kappa$ B activity in retinal vessel ECs [105, 154-156]. Furthermore, ECs cultured in $25-30 \mathrm{mM}$ glucose also show increased NF- $\kappa \mathrm{B}$ activity $[104,105,135,157]$. Whether the apparent discrepancy is due to the species difference or a result of experimental conditions remains to be determined.

Transcription factor proteins that form the AP- 1 dimers are also activated by multiple stimuli mediating several functions [158]. These proteins include the Jun, Fos, and ATF subgroups of transcription factors proteins $[158,159]$. Hyperglycemia activates both NF- $\kappa \mathrm{B}$ and AP- 1 transcription factors via multiple pathways. We have recently shown that MAPK-mediated ECM protein synthesis in ECs is dependent on both NF- $\kappa$ B and AP-1 activation [23]. ET- 1 also increases FN expression through the activation of these transcription factors in cultured ECs and target organs of diabetic complications, retina, kidney, and heart $[21,157]$. NF- $\kappa \mathrm{B}$ is also a redox-sensitive transcription factor which is activated by increased oxidative stress and AGE formation $[55,112,160]$. Several other transcription factors may play regulatory role in these pathways. Recently, a number of clinical trials have shown some promise for the use of triamcinolone acetonide in the management of DR (reviewed in [161]). Triamcinolone acetonide, a synthetic glucocorticoid, has been reported to reduce vascular permeability, hemorrhages, and neovascularization in DR. In addition to regulating VEGF, the mechanisms of action may involve transrepression of 


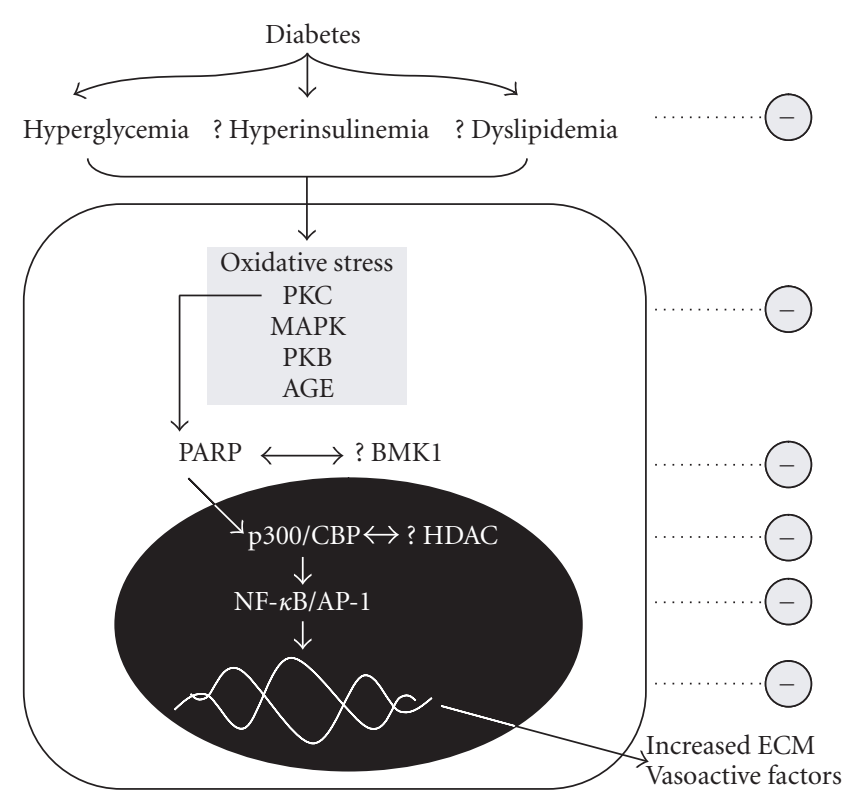

FIgURe 3: Putative signaling mechanisms in vascular ECs and possible treatment targets for DR $(?=$ hypothetical; $\ominus$ = potential therapeutic target, $\mathrm{PARP}=$ poly $(\mathrm{ADP}-$ ribose $)$ polymerase; $\mathrm{AGE}=$ advanced glycation end product, $\mathrm{PKC}=$ protein kinase $\mathrm{C}$; $\mathrm{PKB}=$ protein kinase $\mathrm{B}, \mathrm{ECM}=$ extracellular matrix; $\mathrm{MAPK}=$ mitogenactivated protein kinase, $\mathrm{Ox}=$ oxidative stress, $\mathrm{BMK} 1=$ big MAPK1, $\mathrm{HDAC}=$ histone deacetylase).

both NF- $\kappa$ B and AP-1 $[147,162,163]$. Inactive glucocorticoid receptors are present in the cytoplasm being bound to heat shock protein hsp90 which prevents nuclear translocation. Upon ligand binding (steroid/glucocorticoid), hsp90 dissociates and the receptor/ligand complex translocates to the nucleus. The repression of NF- $\kappa \mathrm{B}$ and AP- 1 by the glucocorticoid receptors is believed to be due to direct interaction of the receptor with the transcription factors.

\subsection{Transcription coactivators}

Histone-dependent packaging of the genomic DNA is a key mechanism in gene regulation. Remodelling of the chromatin in the nucleus, regulated by acetylation and deacetylation of histone residues, is important in allowing access of transcription factors for DNA binding. Acting in opposing manner, histone acetyl transferases (HATs) and histone decetylases (HDACs) control several cellular processes through transcription factors [164]. p300 and related CREB binding protein $(\mathrm{CBP})$ are the best characterized HATs. p300 associates with CBP associated factor (PCAF) and plays a crucial role in cell differentiation, growth, and apoptosis [164]. Transcription factors such as NF- $\kappa \mathrm{B}$ remain inactive, even after nuclear translocation, without association with p300 $[164,165]$. NF- $\kappa \mathrm{B}$ activity in diabetes is regulated by $\mathrm{p} 300$. We have shown that FN expression, in both cultured ECs and in the retina of diabetic rats, is mediated by p 300 induction [104]. It is not clear yet whether HDACs may modulate such pathways. This signaling pathway is modifiable through protein kinase C, protein kinase B, and possible MAPK [104].
These results suggest that diabetes-induced molecular alterations, oxidative stress, PKC and MAPK activation may converge on NF- $\kappa \mathrm{B}$ to mediate increased ECM protein expression in the vascular tissue.

\section{CONCLUDING REMARKS}

Diabetes leads to selective damage to a number of target organs including the retina. Studies have identified common signaling pathways in cultured cells and animal models of diabetes which may in concert lead to the pathogenetic changes in the retinal vasculature. One recurring theme in DR and other complications of diabetes is vascular EC dysfunction. This endotheliopathy is carried out by hyperglycemia-induced changes in vasoregulation (ET$1 / \mathrm{NO}$ ), oxidative stress, and increased polyol pathway. Altered EC function then is precipitated with continued activation of intracellular signaling proteins such as $\mathrm{PKC}, \mathrm{PKB}$, and MAPK, finally culminating in pathological induction of transcription factors such as NF- $\kappa$ B and AP-1. HATs such as p300 may represent upstream regulators of these transcription factors. The concept of such epigenetic regulation of gene transcription is intriguing. One integral question in adequate combat of the secondary complications of diabetes is how does one inhibit such a complex and interrelated signaling cascade? A possible avenue is to identify a point of convergence which may reside at the epigenetic level. The activity (including the specificity) of transcription factors is also dependent on the coactivators in the protein complex. A further grasp of the hyperglycemia-induced transcription machinery (transcription profiling) is crucial to identifying the molecular signature of DR. Future advances in EC biology would greatly enhance our ability to simultaneously inhibit these signaling proteins, and prevent and possibly reverse the adverse effects of chronic diabetes. An outline of the discussed signaling mechanisms and potential treatment targets is shown in Figure 3.

\section{REFERENCES}

[1] F. I. Caird, "The epidemiology of diabetic microangiopathy," Acta Diabetologica Latina, vol. 8, supplement 1, pp. 240-248, 1971.

[2] R. S. Mazze, P. Sinnock, L. Deeb, and J. L. Brimberry, "An epidemiological model for diabetes mellitus in the United States: five major complications," Diabetes Research and Clinical Practice, vol. 1, no. 3, pp. 185-191, 1985.

[3] D. S. Fong, L. Aiello, T. W. Gardner, et al., "Diabetic retinopathy," Diabetes Care, vol. 26, pp. 226-229, 2003.

[4] V. A. Alder, E. N. Su, D. Y. Yu, S. J. Cringle, and P. K. Yu, "Diabetic retinopathy: early functional changes," Clinical and Experimental Pharmacology and Physiology, vol. 24, no. 9-10, pp. 785-788, 1997.

[5] M. D. Davis, "Diabetic retinopathy. A clinical overview," Diabetes Care, vol. 15, no. 12, pp. 1844-1874, 1992.

[6] C. Hudson, "The clinical features and classification of diabetic retinopathy," Ophthalmic and Physiological Optics, vol. 16, supplement 2, pp. 43-48, 1996.

[7] K. A. Neely, D. A. Quillen, A. P. Schachat, T. W. Gardner, and G. W. Blankenship, "Diabetic retinopathy," The Medical Clinics of North America, vol. 82, no. 4, pp. 847-876, 1998. 
[8] F. C. Piccolino, M. Zingirian, and C. Mosci, "Classification of proliferative diabetic retinopathy," Graefe's Archive for Clinical and Experimental Ophthalmology, vol. 225, no. 4, pp. 245250, 1987.

[9] H. F. Spalter, "Diabetic maculopathy," Metabolic, Pediatric and Systemic Ophthalmology, vol. 7, no. 4, pp. 211-215, 1983.

[10] H. Shamoon, H. Duffy, N. Fleischer, et al., "The effect of intensive treatment of diabetes on the development and progression of long-term complications in insulin-dependent diabetes mellitus," New England Journal of Medicine, vol. 329, no. 14, pp. 977-986, 1993.

[11] UK Prospective Diabetes Study (UKPDS) Group, "Effect of intensive blood-glucose control with metformin on complications in overweight patients with type 2 diabetes (UKPDS 34)," The Lancet, vol. 352, no. 9131, pp. 854-865, 1998.

[12] M. Brownlee, "Biochemistry and molecular cell biology of diabetic complications," Nature, vol. 414, no. 6865, pp. 813820, 2001.

[13] Z. A. Khan and S. Chakrabarti, "Endothelins in chronic diabetic complications," Canadian Journal of Physiology and Pharmacology, vol. 81, no. 6, pp. 622-634, 2003.

[14] M. A. van de Ree, M. V. Huisman, F. H. de Man, J. C. van der Vijver, A. E. Meinders, and G. J. Blauw, "Impaired endothelium-dependent vasodilation in type 2 diabetes mellitus and the lack of effect of simvastatin," Cardiovascular Research, vol. 52, no. 2, pp. 299-305, 2001.

[15] G. Dogra, L. Rich, K. Stanton, and G. F. Watts, "Endothelium-dependent and independent vasodilation studied at normoglycaemia in type I diabetes mellitus with and without microalbuminuria," Diabetologia, vol. 44, no. 5, pp. 593-601, 2001.

[16] J. Lambert, M. Aarsen, A. J. Donker, and C. D. Stehouwer, "Endothelium-dependent and -independent vasodilation of large arteries in normoalbuminuric insulin-dependent diabetes mellitus," Arteriosclerosis, Thrombosis, and Vascular Biology, vol. 16, no. 5, pp. 705-711, 1996.

[17] M. T. Johnstone, S. J. Creager, K. M. Scales, J. A. Cusco, B. K. Lee, and M. A. Creager, "Impaired endothelium-dependent vasodilation in patients with insulin- dependent diabetes mellitus," Circulation, vol. 88, no. 6, pp. 2510-2516, 1993.

[18] G. E. McVeigh, G. M. Brennan, G. D. Johnston, et al., "Impaired endothelium-dependent and independent vasodilation in patients with type 2 (non-insulin-dependent) diabetes mellitus," Diabetologia, vol. 35, no. 8, pp. 771-776, 1992.

[19] D. Deng, T. Evans, K. Mukherjee, D. Downey, and S. Chakrabarti, "Diabetes-induced vascular dysfunction in the retina: role of endothelins," Diabetologia, vol. 42, no. 10, pp. 1228-1234, 1999.

[20] M. Cukiernik, S. Mukherjee, D. Downey, and S. Chakabarti, "Heme oxygenase in the retina in diabetes," Current Eye Research, vol. 27, no. 5, pp. 301-308, 2003.

[21] S. Chen, Z. A. Khan, M. Cukiernik, and S. Chakrabarti, "Differential activation of NF- $\kappa$ B and AP-1 in increased fibronectin synthesis in target organs of diabetic complications," American Journal of Physiology. Endocrinology and Metabolism, vol. 284, pp. E1089-E1097, 2003.

[22] Z. A. Khan, B. M. Chan, S. Uniyal, et al., "EDB fibronectin and angiogenesis-a novel mechanistic pathway," Angiogenesis, vol. 8, no. 3, pp. 183-196, 2005.

[23] X. Xin, Z. A. Khan, S. Chen, and S. Chakrabarti, "Extracellular signal-regulated kinase (ERK) in glucose-induced and endothelin-mediated fibronectin synthesis," Laboratory Investigation, vol. 84, pp. 1451-1459, 2004.
[24] S. Chen, M. D. Apostolova, M. G. Cherian, and S. Chakrabarti, "Interaction of endothelin-1 with vasoactive factors in mediating glucose-induced increased permeability in endothelial cells," Laboratory Investigation, vol. 80, no. 8, pp. 1311-1321, 2000.

[25] S. Chen, Z. A. Khan, Y. Barbin, and S. Chakrabarti, "Prooxidant role of heme oxygenase in mediating glucoseinduced endothelial cell damage," Free Radical Research, vol. 38, no. 12, pp. 1301-1310, 2004.

[26] Z. A. Khan, H. Farhangkhoee, and S. Chakrabarti, "Towards newer molecular targets for chronic diabetic complications," Current Vascular Pharmacology, vol. 4, no. 1, pp. 45-57, 2006.

[27] H. Farhangkhoee, Z. A. Khan, S. Mukherjee, et al., "Heme oxygenase in diabetes-induced oxidative stress in the heart," Journal of Molecular and Cellular Cardiology, vol. 35, no. 12, pp. 1439-1448, 2003.

[28] D. S. Gelinas, P. N. Bernatchez, S. Rollin, N. G. Bazan, and M. G. Sirois, "Immediate and delayed VEGF-mediated NO synthesis in endothelial cells: role of PI3K, PKC and PLC pathways," British Journal of Pharmacology, vol. 137, no. 7, pp. 1021-1030, 2002.

[29] R. S. Scotland, M. Morales-Ruiz, Y. Chen, et al., "Functional reconstitution of endothelial nitric oxide synthase reveals the importance of serine 1179 in endothelium-dependent vasomotion," Circulation Research, vol. 90, no. 8, pp. 904-910, 2002.

[30] S. Dimmeler, I. Fleming, B. Fisslthaler, C. Hermann, R. Busse, and A. M. Zeiher, "Activation of nitric oxide synthase in endothelial cells by Akt-dependent phosphorylation," Nature, vol. 399, no. 6736, pp. 601-605, 1999.

[31] S. W. Ryter and R. M. Tyrrell, "The heme synthesis and degradation pathways: role in oxidant sensitivity. Heme oxygenase has both pro- and antioxidant properties," Free Radical Biology and Medicine, vol. 28, no. 2, pp. 289-309, 2000.

[32] D. B. Archer, "Bowman lecture 1998. Diabetic retinopathy: some cellular, molecular and therapeutic considerations," Eye, vol. 13, part 4, pp. 497-523, 1999.

[33] M. Lorenzi and C. Gerhardinger, "Early cellular and molecular changes induced by diabetes in the retina," Diabetologia, vol. 44, no. 7, pp. 791-804, 2001.

[34] S. S. Feman, "The natural history of the first clinically visible features of diabetic retinopathy," Transactions of the American Ophthalmological Society, vol. 92, pp. 745-773, 1994.

[35] M. A. Attawia and R. C. Nayak, "Circulating antipericyte autoantibodies in diabetic retinopathy," Retina, vol. 19, no. 5, pp. 390-400, 1999.

[36] R. C. Nayak, C. D. Agardh, M. G. Kwok, H. Stjernquist, P. J. Farthing-Nayak, and E. Agardh, "Circulating anti-pericyte autoantibodies are present in type 2 diabetic patients and are associated with non-proliferative retinopathy," Diabetologia, vol. 46, no. 4, pp. 511-513, 2003.

[37] G. Allt and J. G. Lawrenson, "Pericytes: cell biology and pathology," Cells Tissues Organs, vol. 169, no. 1, pp. 1-11, 2001.

[38] P. M. Newcomb and I. M. Herman, "Pericyte growth and contractile phenotype: modulation by endothelialsynthesized matrix and comparison with aortic smooth muscle," Journal of Cellular Physiology, vol. 155, no. 2, pp. 385393, 1993.

[39] D. Ruggiero, M. Lecomte, E. Michoud, M. Lagarde, and $\mathrm{N}$. Wiernsperger, "Involvement of cell-cell interactions in the pathogenesis of diabetic retinopathy," Diabetes \& Metabolism, vol. 23, no. 1, pp. 30-42, 1997. 
[40] Z. A. Khan and S. Chakrabarti, "Growth factors in proliferative diabetic retinopathy," Experimental Diabesity Research, vol. 4, no. 4, pp. 287-301, 2003.

[41] C. K. Chee and D. W. Flanagan, "Visual field loss with capillary non-perfusion in preproliferative and early proliferative diabetic retinopathy," British Journal of Ophthalmology, vol. 77, no. 11, pp. 726-730, 1993.

[42] E. M. Kohner and P. Henkind, "Correlation of fluorescein angiogram and retinal digest in diabetic retinopathy," American Journal of Ophthalmology, vol. 69, no. 3, pp. 403-414, 1970.

[43] H. P. Hammes, J. Lin, O. Renner, et al., "Pericytes and the pathogenesis of diabetic retinopathy," Diabetes, vol. 51, no. 10, pp. 3107-3112, 2002.

[44] M. Murata, N. Ohta, S. Fujisawa, et al., "Selective pericyte degeneration in the retinal capillaries of galactose-fed dogs results from apoptosis linked to aldose reductase-catalyzed galactitol accumulation," Journal of Diabetes and Its Complications, vol. 16, no. 5, pp. 363-370, 2002.

[45] J. Cai and M. Boulton, "The pathogenesis of diabetic retinopathy: old concepts and new questions," Eye, vol. 16, no. 3, pp. 242-260, 2002.

[46] T. A. Ciulla, A. Harris, P. Latkany, et al., "Ocular perfusion abnormalities in diabetes," Acta Ophthalmologica Scandinavica, vol. 80, no. 5, pp. 468-477, 2002.

[47] J. A. Colwell, P. D. Winocour, and P. V. Halushka, "Do platelets have anything to do with diabetic microvascular disease?" Diabetes, vol. 32, supplement 2, pp. 14-19, 1983.

[48] K. Yamashiro, A. Tsujikawa, S. Ishida, et al., "Platelets accumulate in the diabetic retinal vasculature following endothelial death and suppress blood-retinal barrier breakdown," American Journal of Pathology, vol. 163, no. 1, pp. 253-259, 2003.

[49] W. Sun, C. Gerhardinger, Z. Dagher, T. Hoehn, and M. Lorenzi, "Aspirin at low-intermediate concentrations protects retinal vessels in experimental diabetic retinopathy through non-platelet-mediated effects," Diabetes, vol. 54, no. 12, pp. 3418-3426, 2005.

[50] M. Matsuoka, N. Ogata, K. Minamino, and M. Matsumura, "Leukostasis and pigment epithelium-derived factor in rat models of diabetic retinopathy," Molecular Vision, vol. 13, pp. 1058-1065, 2007.

[51] S. Schroder, W. Palinski, and G. W. Schmid-Schonbein, "Activated monocytes and granulocytes, capillary nonperfusion, and neovascularization in diabetic retinopathy," American Journal of Pathology, vol. 139, no. 1, pp. 81-100, 1991.

[52] J. M. Hughes, A. Brink, A. N. Witmer, M. Hanraads-de Riemer, I. Klaassen, and R. O. Schlingemann, "Vascular leucocyte adhesion molecules unaltered in the human retina in diabetes," British Journal of Ophthalmology, vol. 88, no. 4, pp. 566-572, 2004.

[53] D. S. McLeod, D. J. Lefer, C. Merges, and G. A. Lutty, "Enhanced expression of intracellular adhesion molecule-1 and P-selectin in the diabetic human retina and choroid," American Journal of Pathology, vol. 147, no. 3, pp. 642-653, 1995.

[54] G. A. Limb, J. Hickman-Casey, R. D. Hollifield, and A. H. Chignell, "Vascular adhesion molecules in vitreous from eyes with proliferative diabetic retinopathy," Investigative Ophthalmology \& Visual Science, vol. 40, no. 10, pp. 2453-2457, 1999.

[55] A. M. Schmidt, O. Hori, J. X. Chen, et al., "Advanced glycation endproducts interacting with their endothelial receptor induce expression of vascular cell adhesion molecule-1 (VCAM-1) in cultured human endothelial cells and in mice.
A potential mechanism for the accelerated vasculopathy of diabetes," Journal of Clinical Investigation, vol. 96, pp. 13951403, 1995.

[56] D. A. Antonetti, E. Lieth, A. J. Barber, and T. W. Gardner, "Molecular mechanisms of vascular permeability in diabetic retinopathy," Seminars in Ophthalmology, vol. 14, no. 4, pp. 240-248, 1999.

[57] I. H. Wallow and R. L. Engerman, "Permeability and patency of retinal blood vessels in experimental diabetes," Investigative Ophthalmology \& Visual Science, vol. 16, no. 5, pp. 447461, 1977.

[58] A. Castillo, J. M. Benitez Del Castillo, D. Diaz, O. Sayagues, J. L. Ruibal, and J. Garcia-Sanchez, "Analysis of the bloodretinal barrier: its relation to clinical and metabolic factors and progression to retinopathy in juvenile diabetics. A 4-year follow-up study," Graefe's Archive for Clinical and Experimental Ophthalmology, vol. 234, no. 4, pp. 246-250, 1996.

[59] J. Cunha-Vaz, C. Lobo, J. Castro Sousa, B. Oliveiros, E. Leite, and J. R. Faria de Abreu, "Progression of retinopathy and alteration of the blood-retinal barrier in patients with type 2 diabetes: a 7-year prospective follow-up study," Graefe's Archive for Clinical and Experimental Ophthalmology, vol. 236, no. 4, pp. 264-268, 1998.

[60] L. Kessel, B. Moldow, J. A. van Best, and B. Sander, "Corneal autofluorescence in relation to permeability of the bloodaqueous barrier in diabetic patients with clinically significant macular edema and in an age-matched control group," Current Eye Research, vol. 26, no. 5, pp. 307-312, 2003.

[61] C. L. Lobo, R. C. Bernardes, J. R. Faria de Abreu, and J. G. Cunha-Vaz, "One-year follow-up of blood-retinal barrier and retinal thickness alterations in patients with type 2 diabetes mellitus and mild nonproliferative retinopathy," Archives of Ophthalmology, vol. 119, no. 10, pp. 1469-1474, 2001.

[62] C. L. Lobo, R. C. Bernardes, J. P. Figueira, J. R. Faria de Abreu, and J. G. Cunha-Vaz, "Three-year follow-up study of bloodretinal barrier and retinal thickness alterations in patients with type 2 diabetes mellitus and mild nonproliferative diabetic retinopathy," Archives of Ophthalmology, vol. 122, no. 2, pp. 211-217, 2004.

[63] B. Sander, M. Larsen, C. Engler, H. Lund-Andersen, and H. H. Parving, "Early changes in diabetic retinopathy: capillary loss and blood-retina barrier permeability in relation to metabolic control," Acta Ophthalmologica, vol. 72, no. 5, pp. 553-559, 1994.

[64] R. Schalnus and C. Ohrloff, "The blood-ocular barrier in type I diabetes without diabetic retinopathy: permeability measurements using fluorophotometry," Ophthalmic Research, vol. 27, supplement 1, pp. 116-123, 1995.

[65] R. Schalnus, C. Ohrloff, E. Jungmann, K. Maass, S. Rinke, and A. Wagner, "Permeability of the blood-retinal barrier and the blood-aqueous barrier in type I diabetes without diabetic retinopathy: simultaneous evaluation with fluorophotometry," German journal of ophthalmology, vol. 2, no. 4-5, pp. 202-206, 1993.

[66] S. Roy and M. Lorenzi, "Early biosynthetic changes in the diabetic-like retinopathy of galactose-fed rats," Diabetologia, vol. 39, no. 6, pp. 735-738, 1996.

[67] S. Roy, M. Maiello, and M. Lorenzi, "Increased expression of basement membrane collagen in human diabetic retinopathy," Journal of Clinical Investigation, vol. 93, no. 1, pp. 438442, 1994. 
[68] S. Roy and T. Sate, "Role of vascular basement membrane components in diabetic microangiopathy," Drug News and Perspectives, vol. 13, no. 2, pp. 91-98, 2000.

[69] S. Roy, T. Sato, G. Paryani, and R. Kao, "Downregulation of fibronectin overexpression reduces basement membrane thickening and vascular lesions in retinas of galactose-fed rats," Diabetes, vol. 52, no. 5, pp. 1229-1234, 2003.

[70] M. D. Siperstein, R. H. Unger, and L. L. Madison, "Studies of muscle capillary basement membranes in normal subjects, diabetic, and prediabetic patients," Journal of Clinical Investigation, vol. 47, no. 9, pp. 1973-1999, 1968.

[71] T. Yamashita and B. Becker, "The basement membrane in the human diabetic eye," Diabetes, vol. 10, pp. 167-174, 1961.

[72] E. Cagliero, M. Maiello, D. Boeri, S. Roy, and M. Lorenzi, "Increased expression of basement membrane components in human endothelial cells cultured in high glucose," Journal of Clinical Investigation, vol. 82, no. 2, pp. 735-738, 1988.

[73] E. Cagliero, T. Roth, S. Roy, and M. Lorenzi, "Characteristics and mechanisms of high-glucose-induced overexpression of basement membrane components in cultured human endothelial cells," Diabetes, vol. 40, no. 1, pp. 102-110, 1991.

[74] H. Hua, H. J. Goldberg, I. G. Fantus, and C. I. Whiteside, "High glucose-enhanced mesangial cell extracellular signalregulated protein kinase activation and $\alpha 1$ (IV) collagen expression in response to endothelin-1: role of specific protein kinase C isozymes," Diabetes, vol. 50, no. 10, pp. 2376-2383, 2001.

[75] T. Nishikawa, I. Giardino, D. Edelstein, and M. Brownlee, "Changes in diabetic retinal matrix protein mRNA levels in a common transgenic mouse strain," Current Eye Research, vol. 21, no. 1, pp. 581-587, 2000.

[76] S. Chen, T. Evans, K. Mukherjee, M. Karmazyn, and S. Chakrabarti, "Diabetes-induced myocardial structural changes: Role of endothelin-1 and its receptors," Journal of Molecular and Cellular Cardiology, vol. 32, no. 9, pp. 16211629, 2000.

[77] T. Evans, D. X. Deng, S. Chen, and S. Chakrabarti, "Endothelin receptor blockade prevents augmented extracellular matrix component mRNA expression and capillary basement membrane thickening in the retina of diabetic and galactosefed rats," Diabetes, vol. 49, no. 4, pp. 662-666, 2000.

[78] A. V. Ljubimov, R. E. Burgeson, R. J. Butkowski, et al., "Basement membrane abnormalities in human eyes with diabetic retinopathy," Journal of Histochemistry and Cytochemistry, vol. 44, no. 12, pp. 1469-1479, 1996.

[79] K. S. Spirin, M. Saghizadeh, S. L. Lewin, L. Zardi, M. C. Kenney, and A. V. Ljubimov, "Basement membrane and growth factor gene expression in normal and diabetic human retinas," Current Eye Research, vol. 18, no. 6, pp. 490-499, 1999.

[80] A. N. Witmer, J. van den Born, G. F. Vrensen, and R. O. Schlingemann, "Vascular localization of heparan sulfate proteoglycans in retinas of patients with diabetes mellitus and in VEGF-induced retinopathy using domain-specific antibodies," Current Eye Research, vol. 22, no. 3, pp. 190-197, 2001.

[81] Z. A. Khan, M. Cukiernik, J. R. Gonder, and S. Chakrabarti, "Oncofetal fibronectin in diabetic retinopathy," Investigative Ophthalmology \& Visual Science, vol. 45, no. 1, pp. 287-295, 2004.

[82] C. G. Schalkwijk and C. D. Stehouwer, "Vascular complications in diabetes mellitus: the role of endothelial dysfunction," Clinical Science, vol. 109, no. 2, pp. 143-159, 2005.

[83] R. J. Boado and W. M. Pardridge, "The brain-type glucose transporter mRNA is specifically expressed at the blood- brain barrier," Biochemical and Biophysical Research Communications, vol. 166, no. 1, pp. 174-179, 1990.

[84] T. B. Choi, R. J. Boado, and W. M. Pardridge, "Blood-brain barrier glucose transporter mRNA is increased in experimental diabetes mellitus," Biochemical and Biophysical Research Communications, vol. 164, no. 1, pp. 375-380, 1989.

[85] J. H. Kinoshita and C. Nishimura, "The involvement of aldose reductase in diabetic complications," Diabetes/Metabolism Reviews, vol. 4, no. 4, pp. 323-337, 1988.

[86] C. Yabe-Nishimura, "Aldose reductase in glucose toxicity: a potential target for the prevention of diabetic complications," Pharmacological Reviews, vol. 50, no. 1, pp. 21-33, 1998.

[87] D. A. Greene, S. Chakrabarti, S. A. Lattimer, and A. A. Sima, "Role of sorbitol accumulation and myo-inositol depletion in paranodal swelling of large myelinated nerve fibers in the insulin-deficient spontaneously diabetic bio-breeding rat. Reversal by insulin replacement, an aldose reductase inhibitor, and myo-inositol," Journal of Clinical Investigation, vol. 79, no. 5, pp. 1479-1485, 1987.

[88] S. Chakrabarti and A. A. Sima, "The effect of myo-inositol treatment on basement membrame thickening in the BB/Wrat retina," Diabetes Research and Clinical Practice, vol. 16, no. 1, pp. 13-17, 1992.

[89] N. Trueblood and R. Ramasamy, "Aldose reductase inhibition improves altered glucose metabolism of isolated diabetic rat hearts," American Journal of Physiology. Heart and Circulatory Physiology, vol. 275, no. 1, part 2, pp. H75-H83, 1998.

[90] K. Sivenius, L. Niskanen, R. Voutilainen-Kaunisto, M. Laakso, and M. Uusitupa, "Aldose reductase gene polymorphisms and susceptibility to microvascular complications in type 2 diabetes," Diabetic Medicine, vol. 21, no. 12, pp. 13251333, 2004.

[91] Y. Wang, M. C. Ng, S. C. Lee, et al., "Phenotypic heterogeneity and associations of two aldose reductase gene polymorphisms with nephropathy and retinopathy in type 2 diabetes," Diabetes Care, vol. 26, no. 8, pp. 2410-2415, 2003.

[92] A. G. Demaine, "Polymorphisms of the aldose reductase gene and susceptibility to diabetic microvascular complications," Current Medicinal Chemistry, vol. 10, no. 15, pp. 1389-1398, 2003.

[93] Sorbinil Retinopathy Trial Research Group, "A randomized trial of sorbinil, an aldose reductase inhibitor, in diabetic retinopathy," Archives of Ophthalmology, vol. 108, no. 9, pp. 1234-1244, 1990.

[94] W. Sun, P. J. Oates, J. B. Coutcher, C. Gerhardinger, and M. Lorenzi, "A selective aldose reductase inhibitor of a new structural class prevents or reverses early retinal abnormalities in experimental diabetic retinopathy," Diabetes, vol. 55, no. 10, pp. 2757-2762, 2006.

[95] S. P. Wolff, "Diabetes mellitus and free radicals. Free radicals, transition metals and oxidative stress in the aetiology of diabetes mellitus and complications," British Medical Bulletin, vol. 49, no. 3, pp. 642-652, 1993.

[96] T. Nishikawa, D. Edelstein, X. L. Du, et al., "Normalizing mitochondrial superoxide production blocks three pathways of hyperglycaemic damage," Nature, vol. 404, no. 6779, pp. 787790, 2000.

[97] H. P. Hammes, X. Du, D. Edelstein, et al., "Benfotiamine blocks three major pathways of hyperglycemic damage and prevents experimental diabetic retinopathy," Nature Medicine, vol. 9, no. 3, pp. 294-299, 2003.

[98] A. M. Zafari, M. Ushio-Fukai, M. Akers, et al., "Role of NADH/NADPH oxidase-derived $\mathrm{H} 2 \mathrm{O} 2$ in angiotensin 
II-induced vascular hypertrophy," Hypertension, vol. 32, no. 3, pp. 488-495, 1998.

[99] A. Warnholtz, G. Nickenig, E. Schulz, et al., "Increased $\mathrm{NADH}$-oxidase-mediated superoxide production in the early stages of atherosclerosis: evidence for involvement of the renin-angiotensin system," Circulation, vol. 99, no. 15, pp. 2027-2033, 1999.

[100] H. Farhangkhoee, Z. A. Khan, Y. Barbin, and S. Chakrabarti, "Glucose-induced up-regulation of CD36 mediates oxidative stress and microvascular endothelial cell dysfunction," Diabetologia, vol. 48, no. 7, pp. 1401-1410, 2005.

[101] S. Parthasarathy, E. Wieland, and D. Steinberg, "A role for endothelial cell lipoxygenase in the oxidative modification of low density lipoprotein," Proceedings of the National Academy of Sciences of the United States of America, vol. 86, no. 3, pp. 1046-1050, 1989.

[102] P. Decker and S. Muller, "Modulating poly (ADP-ribose) polymerase activity: potential for the prevention and therapy of pathogenic situations involving DNA damage and oxidative stress," Current Pharmaceutical Biotechnology, vol. 3, no. 3, pp. 275-283, 2002.

[103] I. G. Obrosova, P. Pacher, C. Szabo, et al., "Aldose reductase inhibition counteracts oxidative-nitrosative stress and poly(ADP-ribose) polymerase activation in tissue sites for diabetes complications," Diabetes, vol. 54, no. 1, pp. 234-242, 2005.

[104] H. Kaur, S. Chen, X. Xin, J. Chiu, Z. A. Khan, and S. Chakrabarti, "Diabetes-induced extracellular matrix protein expression is mediated by transcription coactivator p300," Diabetes, vol. 55, no. 11, pp. 3104-3111, 2006.

[105] L. Zheng, C. Szabo, and T. S. Kern, "Poly(ADP-ribose) polymerase is involved in the development of diabetic retinopathy via regulation of nuclear factor- $\kappa \mathrm{B}$," Diabetes, vol. 53, pp. 2960-2967, 2004.

[106] P. O. Hassa, S. S. Haenni, C. Buerki, et al., "Acetylation of poly(ADP-ribose) polymerase-1 by p300/CREB-binding protein regulates coactivation of NF- $\kappa \mathrm{B}$-dependent transcription," Journal of biological chemistry, vol. 280, no. 49, pp. 40450-40464, 2005.

[107] K. Ota, M. Kameoka, Y. Tanaka, A. Itaya, and K. Yoshihara, "Expression of histone acetyltransferases was down-regulated in poly(ADP-ribose) polymerase-1-deficient murine cells," Biochemical and Biophysical Research Communications, vol. 310, no. 2, pp. 312-317, 2003.

[108] H. Vlassara, "Recent progress in advanced glycation end products and diabetic complications," Diabetes, vol. 46, supplement 2, pp. S19-S25, 1997.

[109] H. Vlassara, "The AGE-receptor in the pathogenesis of diabetic complications," Diabetes/Metabolism Research and Reviews, vol. 17, no. 6, pp. 436-443, 2001.

[110] A. Bierhaus, M. A. Hofmann, R. Ziegler, and P. P. Nawroth, "AGEs and their interaction with AGE-receptors in vascular disease and diabetes mellitus. I. The AGE concept," Cardiovascular Research, vol. 37, no. 3, pp. 586-600, 1998.

[111] A. W. Stitt, C. He, and H. Vlassara, "Characterization of the advanced glycation end-product receptor complex in human vascular endothelial cells," Biochemical and Biophysical Research Communications, vol. 256, no. 3, pp. 549-556, 1999.

[112] A. W. Stitt, Y. M. Li, T. A. Gardiner, R. Bucala, D. B. Archer, and $\mathrm{H}$. Vlassara, "Advanced glycation end products (AGEs) co-localize with AGE receptors in the retinal vasculature of diabetic and of AGE-infused rats ," The American Journal of Pathology, vol. 150, pp. 523-531, 1997.
[113] A. M. Schmidt, O. Hori, R. Cao, et al., "RAGE: a novel cellular receptor for advanced glycation end products," Diabetes, vol. 45, supplement 3, pp. S77-S80, 1996.

[114] C. Esposito, H. Gerlach, J. Brett, D. Stern, and H. Vlassara, "Endothelial receptor-mediated binding of glucose-modified albumin is associated with increased monolayer permeability and modulation of cell surface coagulant properties," Journal of Experimental Medicine, vol. 170, no. 4, pp. 1387-1407, 1989.

[115] S. Yamagishi, H. Yonekura, Y. Yamamoto, et al., "Advanced glycation end products-driven angiogenesis in vitro: induction of the growth and tube formation of human microvascular endothelial cells through autocrine vascular endothelial growth factor," Journal of Biological Chemistry, vol. 272, no. 13, pp. 8723-8730, 1997.

[116] S. Vasan, P. G. Foiles, and H. W. Founds, "Therapeutic potential of AGE inhibitors and breakers of AGE protein cross-links," Expert Opinion on Investigational Drugs, vol. 10, no. 11, pp. 1977-1987, 2001.

[117] X. Xu, Z. Li, D. Luo, et al., "Exogenous advanced glycosylation end products induce diabetes-like vascular dysfunction in normal rats: a factor in diabetic retinopathy," Graefe's Archive for Clinical and Experimental Ophthalmology, vol. 241, no. 1, pp. 56-62, 2003.

[118] T. A. Kalfa, M. E. Gerritsen, E. C. Carlson, A. J. Binstock, and E. C. Tsilibary, "Altered proliferation of retinal microvascular cells on glycated matrix," Investigative Ophthalmology \& Visual Science, vol. 36, no. 12, pp. 2358-2367, 1995.

[119] T. S. Kern and R. L. Engerman, "Pharmacological inhibition of diabetic retinopathy: aminoguanidine and aspirin," Diabetes, vol. 50, no. 7, pp. 1636-1642, 2001.

[120] X. Xin, Z. A. Khan, S. Chen, and S. Chakrabarti, "Glucoseinduced Akt1 activation mediates fibronectin synthesis in endothelial cells," Diabetologia, vol. 48, no. 11, pp. 2428-2436, 2005.

[121] Z. A. Khan, Y. P. Barbin, H. Farhangkhoee, N. Beier, W. Scholz, and S. Chakrabarti, "Glucose-induced serum- and glucocorticoid-regulated kinase activation in oncofetal fibronectin expression," Biochemical and Biophysical Research Communications, vol. 329, no. 1, pp. 275-280, 2005.

[122] Y. Nishizuka, "Intracellular signaling by hydrolysis of phospholipids and activation of protein kinase C," Science, vol. 258, no. 5082, pp. 607-614, 1992.

[123] H. Ishii, D. Koya, and G. L. King, "Protein kinase C activation and its role in the development of vascular complications in diabetes mellitus," Journal of Molecular Medicine, vol. 76, no. 1, pp. 21-31, 1998.

[124] D. Koya and G. L. King, "Protein kinase C activation and the development of diabetic complications," Diabetes, vol. 47, no. 6, pp. 859-866, 1998.

[125] I. Idris, S. Gray, and R. Donnelly, "Protein kinase C activation: isozyme-specific effects on metabolism and cardiovascular complications in diabetes," Diabetologia, vol. 44, no. 6, pp. 659-673, 2001.

[126] T. Inoguchi, R. Battan, E. Handler, J. R. Sportsman, W. Heath, and G. L. King, "Preferential elevation of protein kinase C isoform $\beta$ II and diacylglycerol levels in the aorta and heart of diabetic rats: differential reversibility to glycemic control by islet cell transplantation," Proceedings of the National Academy of Sciences of the United States of America, vol. 89, pp. 11059-11063, 1992.

[127] T. Shiba, T. Inoguchi, J. R. Sportsman, W. F. Heath, S. Bursell, and G. L. King, "Correlation of diacylglycerol level 
and protein kinase $\mathrm{C}$ activity in rat retina to retinal circulation," American Journal of Physiology. Endocrinology and Metabolism, vol. 265, no. 5, part 1, pp. E783-E793, 1993.

[128] P. Xia, T. Inoguchi, T. S. Kern, R. L. Engerman, P. J. Oates, and G. L. King, "Characterization of the mechanism for the chronic activation of diacylglycerol-protein kinase $\mathrm{C}$ pathway in diabetes and hypergalactosemia," Diabetes, vol. 43, no. 9, pp. 1122-1129, 1994.

[129] Q. Huang and Y. Yuan, "Interaction of PKC and NOS in signal transduction of microvascular hyperpermeability," American Journal of Physiology. Heart and Circulatory Physiology, vol. 273, no. 5, pp. H2442-H2451, 1997.

[130] F. Pomero, A. Allione, E. Beltramo, et al., "Effects of protein kinase $\mathrm{C}$ inhibition and activation on proliferation and apoptosis of bovine retinal pericytes," Diabetologia, vol. 46, no. 3, pp. 416-419, 2003.

[131] J. Y. Park, N. Takahara, A. Gabriele, et al., "Induction of endothelin-1 expression by glucose an effect of protein kinase C activation," Diabetes, vol. 49, no. 7, pp. 1239-1248, 2000.

[132] P. Xia, L. P. Aiello, H. Ishii, et al., "Characterization of vascular endothelial growth factor's effect on the activation of protein kinase C, its isoforms, and endothelial cell growth," Journal of Clinical Investigation, vol. 98, no. 9, pp. 2018-2026, 1996.

[133] L. P. Aiello, S. E. Bursell, A. Clermont, et al., "Vascular endothelial growth factor-induced retinal permeability is mediated by protein kinase $\mathrm{C}$ in vivo and suppressed by an orally effective $\beta$-isoform-selective inhibitor," Diabetes, vol. 46, no. 9, pp. 1473-1480, 1997.

[134] H. Ishii, M. R. Jirousek, D. Koya, et al., "Amelioration of vascular dysfunctions in diabetic rats by an oral PKC $\beta$ inhibitor," Science, vol. 272, no. 5262, pp. 728-731, 1996.

[135] R. A. Kowiuru, M. R. Jirousek, L. Stramm, N. Farid, R. L. Engerman, and T. S. Kern, "Abnormalities of retinal metabolism in diabetes or experimental galactosemia: v. relationship between protein kinase C and APTases," Diabetes, vol. 47, no. 3, pp. 464-469, 1998.

[136] R. P. Danis, D. P. Bingaman, M. Jirousek, and Y. Yang, "Inhibition of intraocular neovascularization caused by retinal ischemia in pigs by PKC $\beta$ inhibition with LY333531," Investigative ophthalmology \& visual sciencei, vol. 39, no. 1, pp. 171-179, 1998.

[137] M. A. Cotter, A. M. Jack, and N. E. Cameron, "Effects of the protein kinase C $\beta$ inhibitor LY333531 on neural and vascular function in rats with streptozotocin-induced diabetes," Clinical Science, vol. 103, no. 3, pp. 311-321, 2002.

[138] The PKC-DRS Study Group, “The effect of ruboxistaurin on visual loss in patients with moderately severe to very severe nonproliferative diabetic retinopathy: initial results of the protein kinase $\mathrm{C} \beta$ inhibitor diabetic retinopathy study (PKC-DRS) multicenter randomized clinical trial," Diabetes, vol. 54, no. 7, pp. 2188-2197, 2005.

[139] L. P. Aiello, M. D. Davis, A. Girach, et al., "Effect of ruboxistaurin on visual loss in patients with diabetic retinopathy," Ophthalmology, vol. 113, no. 12, pp. 2221-2230, 2006.

[140] D. R. Tomlinson, "Mitogen-activated protein kinases as glucose transducers for diabetic complications," Diabetologia, vol. 42, no. 11, pp. 1271-1281, 1999.

[141] M. Awazu, K. Ishikura, M. Hida, and M. Hoshiya, "Mechanisms of mitogen-activated protein kinase activation in experimental diabetes," Journal of the American Society of Nephrology, vol. 10, no. 4, pp. 738-745, 1999.
[142] G. Pearson, F. Robinson, T. B. Gibson, et al., "Mitogenactivated protein (MAP) kinase pathways: regulation and physiological," Endocrine Reviews, vol. 22, no. 2, pp. 153-183, 2001.

[143] H. Fujita, S. Omori, K. Ishikura, M. Hida, and M. Awazu, "ERK and p38 mediate high-glucose-induced hypertrophy and TGF- $\beta$ expression in renal tubular cells," American Journal of Physiology. Renal Physiology, vol. 286, pp. F120-F126, 2004.

[144] M. Toyoda, D. Suzuki, M. Honma, et al., "High expression of PKC-MAPK pathway mRNAs correlates with glomerular lesions in human diabetic nephropathy," Kidney International, vol. 66, pp. 1107-1114, 2004.

[145] C. Liebmann, "Regulation of MAP kinase activity by peptide receptor signalling pathway: paradigms of multiplicity," Cellular Signalling, vol. 13, no. 11, pp. 777-785, 2001.

[146] W. Lui, A. Schoenkerman, and W. L. Lowe Jr., "Activation of members of the mitogen-activated protein kinase family by glucose in endothelial cells," American Journal of Physiology. Endocrinology and Metabolism, vol. 279, no. 4, pp. E782E790, 2000.

[147] M. Hayashi, S. W. Kim, K. Imanaka-Yoshida, et al., "Targeted deletion of BMK1/ERK5 in adult mice perturbs vascular integrity and leads to endothelial failure," Journal of Clinical Investigation, vol. 113, pp. 1138-1148, 2004.

[148] E. N. Olson, "Undermining the endothelium by ablation of MAPK-MEF2 signaling," Journal of Clinical Investigation, vol. 113, pp. 1110-1112, 2004.

[149] M. P. Scheid and J. R. Woodgett, "PKB/AKT: functional insights from genetic models," Nature Reviews Molecular Cell Biology, vol. 2, no. 10, pp. 760-768, 2001.

[150] M. Pap and G. M. Cooper, "Role of glycogen synthase kinase3 in the phosphatidylinositol 3-kinase/Akt cell survival pathway," Journal of Biological Chemistry, vol. 273, no. 32, pp. 19929-19932, 1998.

[151] P. A. Baeuerle, "Pro-inflammatory signaling: last pieces in the NF- $\kappa$ B puzzle?” Current Biology, vol. 8, no. 1, pp. R19-R22, 1998.

[152] P. Quehenberger, A. Bierhaus, P. Fasching, et al., "Endothelin 1 transcription is controlled by nuclear factor- $\kappa \mathrm{B}$ in AGEstimulated cultured endothelial cells," Diabetes, vol. 49, no. 9, pp. 1561-1570, 2000.

[153] G. Romeo, W. H. Liu, V. Asnaghi, T. S. Kern, and M. Lorenzi, "Activation of nuclear factor- $\kappa \mathrm{B}$ induced by diabetes and high glucose regulates a proapoptotic program in retinal pericytes," Diabetes, vol. 51, no. 7, pp. 2241-2248, 2002.

[154] C. Harada, T. Harada, Y. Mitamura, et al., "Diverse NF- $\kappa$ B expression in epiretinal membranes after human diabetic retinopathy and proliferative vitreoretinopathy," Molecular Vision, vol. 10, pp. 31-36, 2004.

[155] Y. Mitamura, T. Harada, C. Harada, et al., "NF- $\kappa$ B in epiretinal membranes after human diabetic retinopathy," Diabetologia, vol. 46, no. 5, pp. 699-703, 2003.

[156] L. Zheng, S. J. Howell, D. A. Hatala, K. Huang, and T. S. Kern, "Salicylate-based anti-inflammatory drugs inhibit the early lesion of diabetic retinopathy," Diabetes, vol. 56, no. 2, pp. 337-345, 2007.

[157] S. Chen, S. Mukherjee, C. Chakraborty, and S. Chakrabarti, "High glucose-induced, endothelin-dependent fibronectin synthesis is mediated via NF- $\kappa \mathrm{B}$ and AP-1," American Journal of Physiology. Cell Physiology, vol. 284, no. 2, pp. C263-C272, 2003. 
[158] E. Shaulian and M. Karin, "AP-1 in cell proliferation and survival,” Oncogene, vol. 20, no. 19, pp. 2390-2400, 2001.

[159] Y. Chinenov and T. K. Kerppola, "Close encounters of many kinds: fos-jun interactions that mediate transcription regulatory specificity," Oncogene, vol. 20, no. 19, pp. 2438-2452, 2001.

[160] M. A. Glomb and V. M. Monnier, "Mechanism of protein modification by glyoxal and glycolaldehyde, reactive intermediates of the maillard reaction," Journal of Biological Chemistry, vol. 270, no. 17, pp. 10017-10026, 1995.

[161] J. B. Jonas, "Intravitreal triamcinolone acetonide for diabetic retinopathy," Developments in Ophthalmology, vol. 39, pp. 96-110, 2007.

[162] P. J. Barnes, "Anti-inflammatory actions of glucocorticoids: molecular mechanisms," Clinical Science, vol. 94, pp. 557572, 1998.

[163] I. M. Adcock, K. Ito, and P. J. Barnes, "Glucocorticoids: effects on gene transcription," Proceedings of the American Thoracic Society, vol. 1, pp. 247-254, 2004.

[164] E. Kalkhoven, "CBP and p300: HATs for different occasions," Biochemical Pharmacology, vol. 68, no. 6, pp. 1145-1155, 2004.

[165] R. H. Goodman and S. Smolik, "CBP/p300 in cell growth, transformation, and development," Genes \& Development, vol. 14, no. 13, pp. 1553-1577, 2000.

\section{AUTHOR CONTACT INFORMATION}

Zia A. Khan: Department of Pathology, University of Western Ontario, London, Ontario, Canada N6A 5C1; zia.khan@schulich.uwo.ca

Subrata Chakrabarti: Department of Pathology, University of Western Ontario, London, Ontario, Canada N6A 5C1;

subrata.chakrabarti@schulich.uwo.ca 


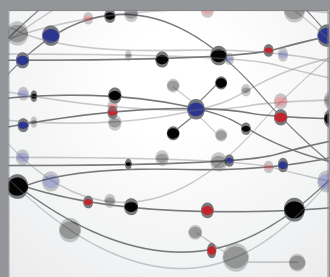

The Scientific World Journal
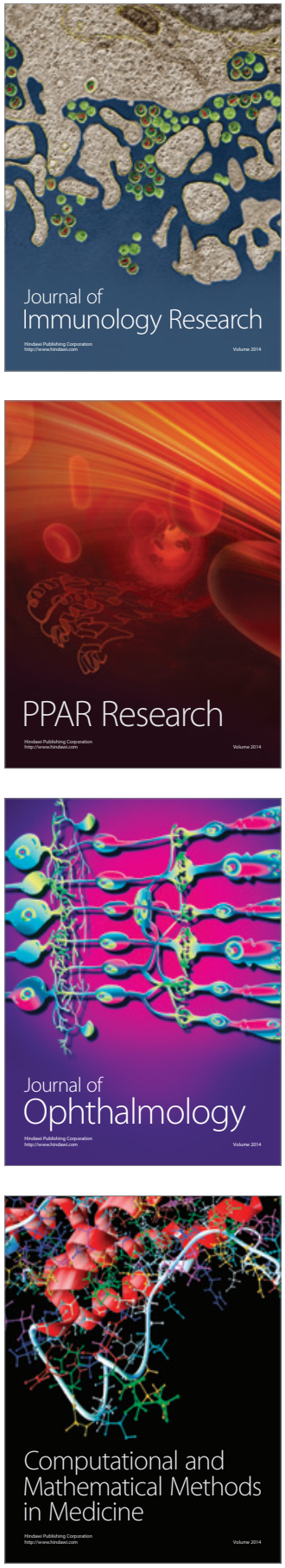

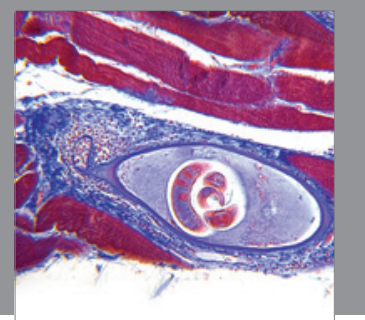

Gastroenterology

Research and Practice
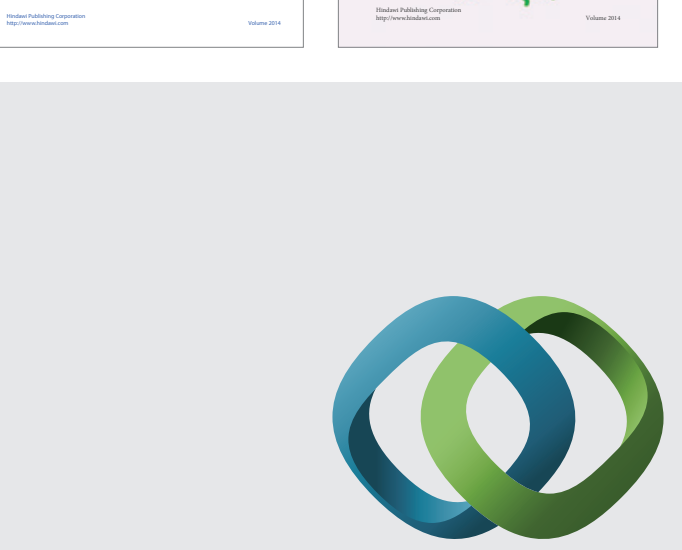

\section{Hindawi}

Submit your manuscripts at

http://www.hindawi.com
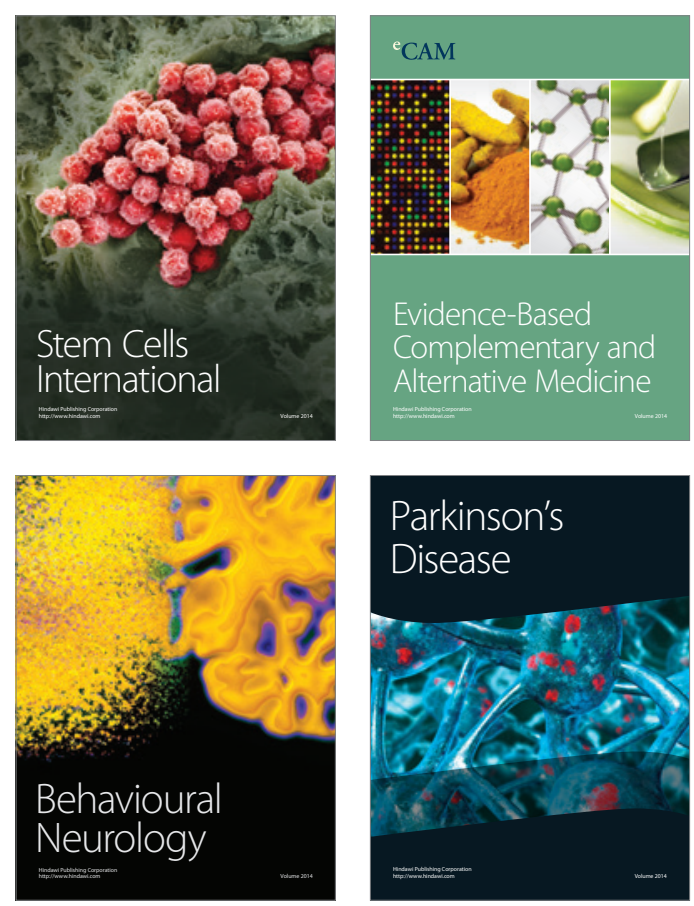

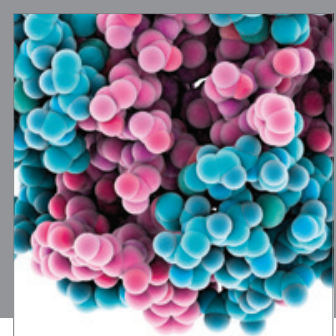

Journal of
Diabetes Research

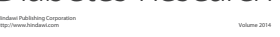

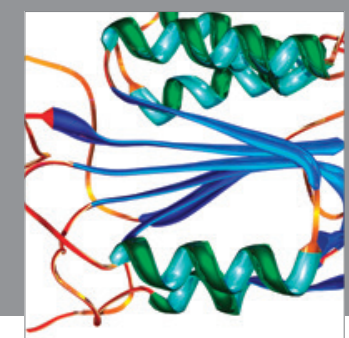

Disease Markers
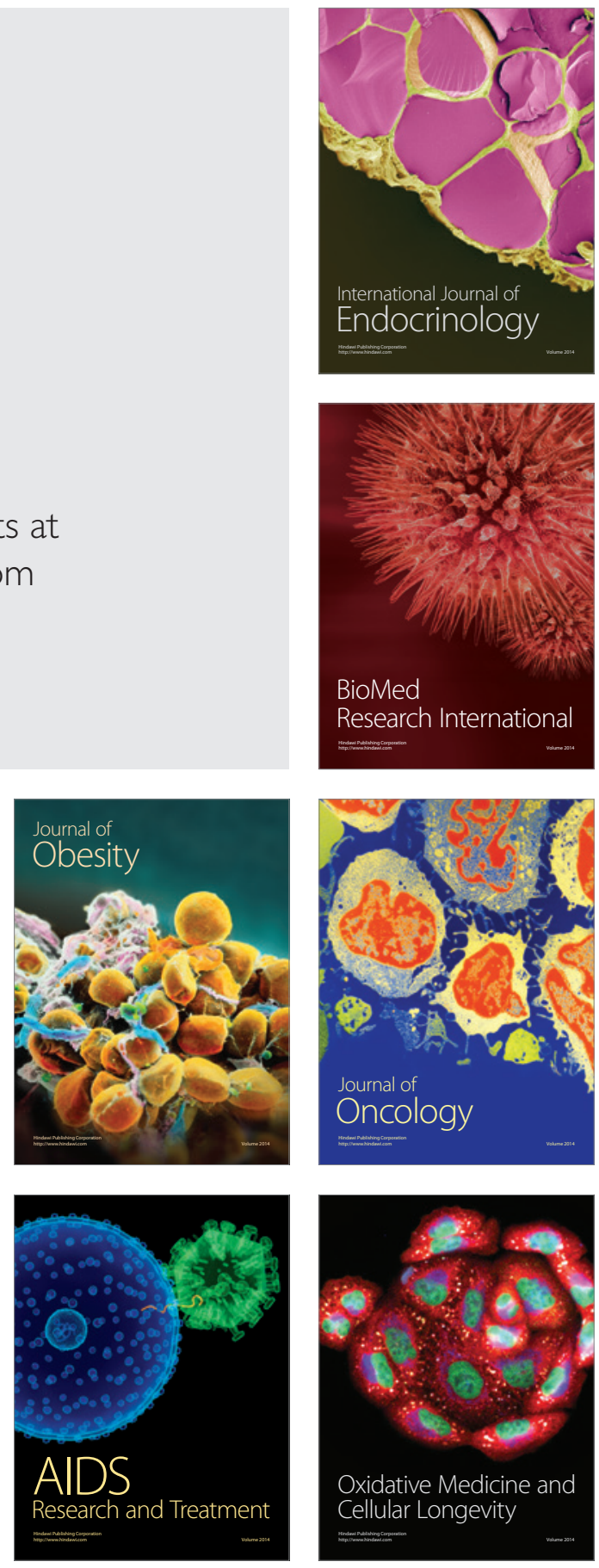